\title{
ARRAY DATA PROCESSING TECHNIQUES APPLIED TO LONG-PERIOD SHEAR WAVES A'T FENNOSCANDIAN SEISMOGRAPH STATIONS
}

\author{
By JAMES H. WhITCOMB
}

\begin{abstract}
Array data processing is applied to long-period records of $S$ waves at a network of five Fennoscandian seismograph stations (Uppsala, Umeå, Nurmij̈̈̈rvi, Kongsberg, Copenhagen) with a maximum separation of $1300 \mathrm{~km}$. Records of five earthquakes and one underground explosion are included in the study. The $S$ motion is resolved into $S H$ and $S V$, and after appropriate time shifts the individual traces are summed, both directly and after weighting.

In general, high signal correlation exists among the different stations involved resulting in more accurate time readings, especially for records which have amplifudes that are too small to be read normally. S-wave station residuals correlate with the general crustal type under each station. In addition, the Fennoscandian shield may have a higher $\mathrm{SH} / \mathrm{SV}$ velocity ratio than the adjacent tectonic area to the northwest. SV-to-P conversion at the base of the crust can seriously interfere with picking the onset of $S$ in normal record reading.

The study demonstrates that, for epicentral distances beyond about $30^{\circ}$, existing networks of seismograph stations can be successfully used for array processing of long-period arrivals, especially the $S$ arrivals.
\end{abstract}

\section{INTRODUCTION}

Array digital processing has been extensively applied to $P$-wave arrivals at a number of arrays such as LASA in Montana. These techniques have produced significant improvements in the signal-to-noise ratio of seismic recordings and thus have improved readings of first arrivals, lowered the threshold of detectability, and sharpened recordings of later arrivals of the $P$-wave train. The LASA-type array, which involves large numbers of seismometers and a great deal of supporting equipment, is prohibitively expensive for the normal seismograph center. Recently, a paper was published by Husebye and Jansson (1966) showing that array processing techniques could be applied to a "super-large aperture seismic array" (SLASA), consisting of verticalcomponent, short-period seismometers at the Swedish seismograph stations, which have a maximum separation of about $1300 \mathrm{~km}$. This work has greatly widened the possibilities for array processing using existing equipment in areas where there is a high density of seismograph stations.

Because the SLASA concept can be applied to short-period, $P$-wave arrivals, it appears probable that arrays of several hundred kilometers can also be used with $S$-wave arrivals. Most $S$-wave energy from earthquakes is relatively long period, often around 10 seconds. Therefore, long-period records provide the best source for earthquake $S$-wave study. Visual observations of $S$-wave similarity between stations have repeatedly been made on the long-period instruments in Sweden (Prof. M. Båth, personal communication). Some initial work has been reported on long-period array analysis at an extended Tonto Forest array in Arizona (Baker, Bonner, and Roden, 1966) and at LASA in Montana (Capon, Greenfield, and Lacoss, 1966), and their signal-to-noise improvements indicate a high correlation of $S$ over the arrays. The extended Tonto Forest and LASA arrays have a maximum diameter of about $200 \mathrm{~km}$ 
compared to a maximum of about $1000 \mathrm{~km}$ for the Scandinavian array which is analyzed here. If the array concept can be successfully extended to long-period recordings made at intervals of several hundred kilometers, ready-made networks of existing stations can be used for array processing of arrivals in the long-period range, especially $S$ arrivals.

One of the primary motivations for using arrays on $S$-wave arrivals is to overcome

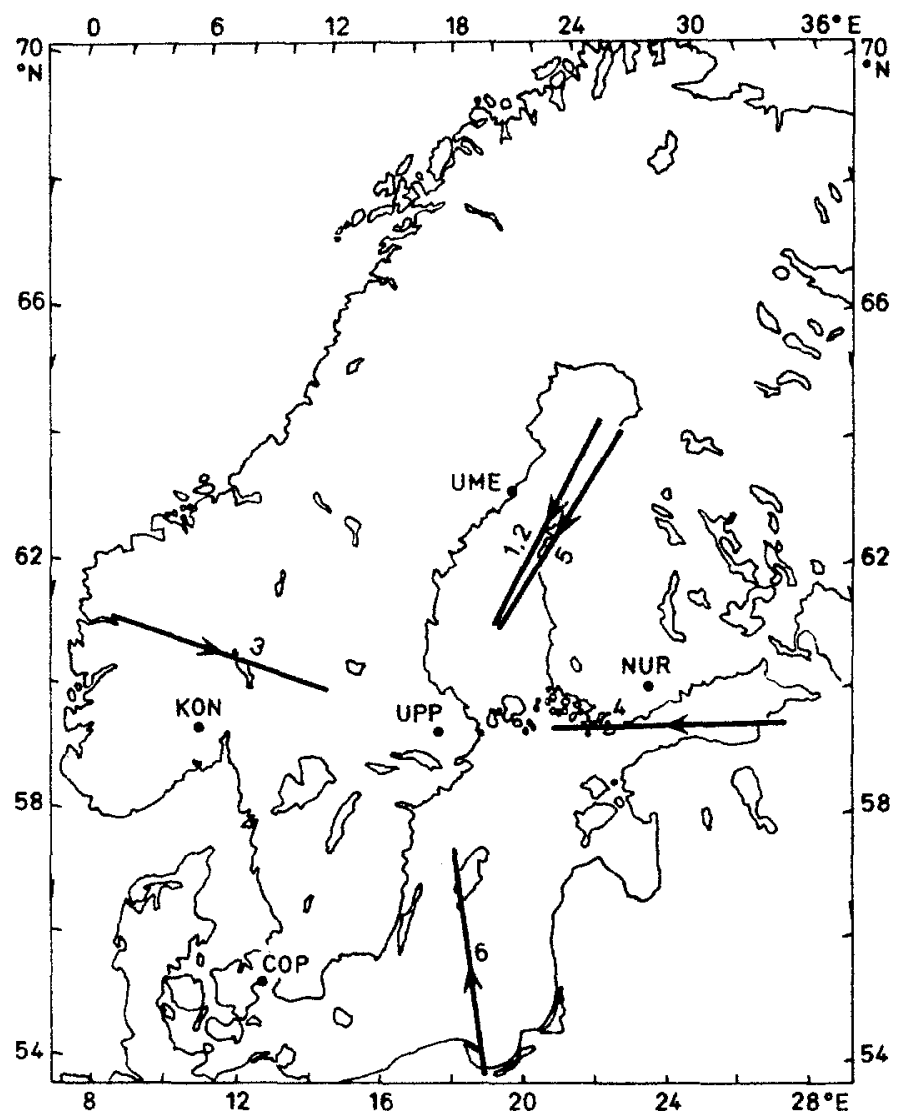

Fia. 1. Station location reference map showing the direction of arrival of the events relative to Uppsala.

the problem of the $S$ wave's large travel-time residuals which pose an obstruction to more accurate knowledge of the Earth's interior. Husebye (1965, p. 1028) has shown that the travel-time residuals from the Jeffreys-Bullen (1940) tables for the $S$ waves are commonly four times larger than those of the $P$-wave arrivals. Thus, our knowledge of $S$-wave velocity and associated elastic parameters in the Earth's interior may be limited by inaccurate reading of $S$-wave times. The larger $S$ residuals, as compared to $P$ residuals, can be attributed to (1) the long period of the normal $S$ wave which, combined with the gradual onset of most $S$ waves, makes it difficult to pick the exact beginning of the arrival, (2) reduced reading accuracy due to the lower long-period recorder speeds, (3) motion on the seismogram from earlier arrivals which interfere with the $S$-wave arrival, and (4) real delays caused by unknown geological variations along wave paths to the different stations. Of these four causes, effects of the first 
three can be determined and hopefully reduced by array processing with digital methods. Another application for array processing of $S$ waves would be to clarify first motions of the $S$-wave train. For focal mechanism studies, first motion observations of $S$ waves from individual stations are less reliable than observations of polarization because of the already existing motion on the seismogram (Bath, 1961, p. 122). If this existing motion is incoherent or has a different apparent velocity than $S$, array analysis would suppress it in favor of the $S$ first motion. In addition, there is current interest in using $S$ waves to distinguish between events of natural and artificial origin for nuclear test-ban monitoring.

This paper attempts to extend the array analysis concept to long-period $S$ waves. The array consists of existing Fennoscandian seismograph stations with a maximum separation of $1000 \mathrm{~km}\left(9^{\circ}\right)$, and the correlation of the $S$-wave signal across this very large array is of primary concern for the success of the method.

\section{The Array and the Events Used}

Five Fennoscandian seismograph stations given in Table 1 are used for the longperiod array. As can be seen in Figure 1, the stations give a reasonably even location

TABLE 1

\begin{tabular}{lllr}
\multicolumn{4}{c}{ Station Locations } \\
\hline Name & Designation & Latitude & Longitude \\
\hline Uppsala, Sweden & UPP & $59.9^{\circ} \mathrm{N}$ & $17.6^{\circ} \mathrm{E}$ \\
Umeå, Sweden & UME & $63.8^{\circ} \mathrm{N}$ & $20.2^{\circ} \mathrm{E}$ \\
Nurmijärvi, Finland & NUR & $60.5^{\circ} \mathrm{N}$ & $24.7^{\circ} \mathrm{E}$ \\
Kongsberg, Norway & KON & $59.7^{\circ} \mathrm{N}$ & $9.6^{\circ} \mathrm{E}$ \\
Copenhagen, Denmark & COP & $55.7^{\circ} \mathrm{N}$ & $12.4^{\circ} \mathrm{E}$ \\
\hline
\end{tabular}

distribution with the longest dimension, about $9^{\circ}$, between UME and COP, with UPP occupying a central location between the other four. All of the stations except Uppsala $\left(T_{0}=15 \mathrm{sec}, T_{g}=90 \mathrm{sec}\right)$ have World-Wide Standard Seismograph instruments $\left(T_{0}=15 \mathrm{sec}, T_{g}=100 \mathrm{sec}\right)$, and the recordings used here, except for one instance mentioned later, are from Press-Ewing-type, long-period seismometers. This is advantageous because a seismometer acts as a linear filter, and coherent seismic arrivals at the array will still be coherent after passage through identical linear filters. Thus, the use of essentially identical instruments eliminates the need for correcting the seismic time series for instrument response. The response characteristics of the longperiod Press-Ewing-type seismometers used are shown in Figure 2.

Six seismic events are chosen to test the array and the amplitudes of their $S$ waves range from large and easily discernible to weak. The events are picked primarily on the basis of magnitude between 5.5 and 6.6, and a varied azimuth and distance distribution. Aside from this, events are randomly chosen and test records have not been intentionally selected for good correlation between stations. Parameters for the six events (presented in Table 2) are taken from bulletins of the USCGS and the Seismological Institute in Uppsala (values from the Uppsala bulletin are indicated by (UPP) in the table). Magnitudes which are not from the Uppsala Bulletin are calculated from the USCGS values with the relation found by Korkman (1968) between USCGS magnitudes and Uppsala's $M$. The foci are at depths of $30 \mathrm{~km}$ or less, except for Case 3 in Nicaragua which is at $70 \mathrm{~km}$. Case 5 at Novaya Zemlya is an underground nuclear explosion of unusually large size with magnitude 6.6 (UPP). 
Magnitudes for the other events range from 5.5 to 6.2 and only in Cases 1,5 , and 6 are the $S$-wave amplitudes large enough for arrival times to be picked and published in the Uppsala Bulletin. Epicentral distances and azimuths of the six events from the five array stations are given in Table 3.

\section{Techniques of Analysis}

A prime prerequisite for applying array techniques to seismic time series is that signals should have a high correlation between stations. But this requirement is not

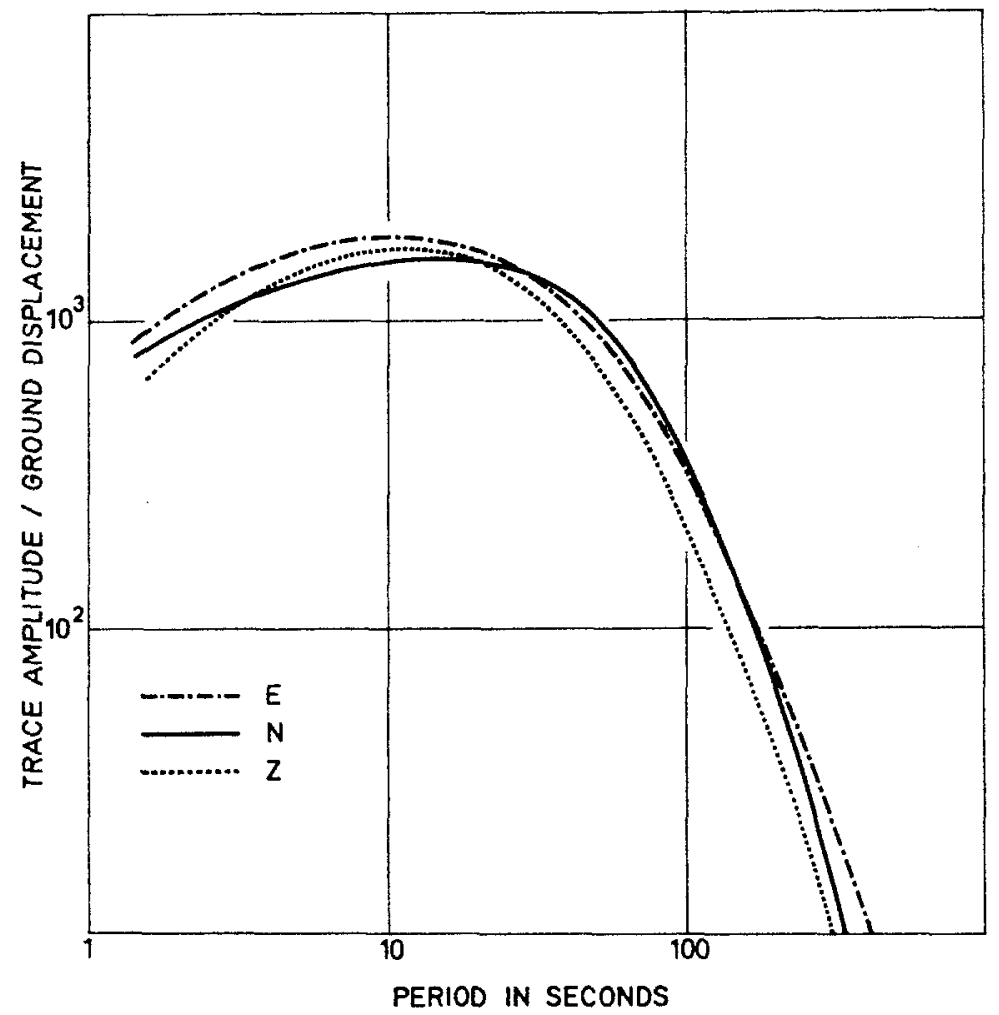

Frg. 2. Long-period, Press-Ewing seismometer characteristics for Uppsala $\left(T_{0}=15 \mathrm{sec}, T_{g}=90 \mathrm{sec}\right)$.

always satisfied for an array with an areal extent of several hundred kilometers because of different crustal and coupling conditions at each station. Therefore, the stations to be used for an array must be tested for signal correlation with good arrivals before applying the array process to more difficult cases. The common measures of signal statistics used to demonstrate correlation are normalized cross-correlation, coherency, and phase lag. The definition of these quantities and the methods for their estimation are described in the Appendix.

The signal is defined as the response of the array instruments to the $S$-wave arrival, which is assumed to have uniform character, but not necessarily uniform amplitude, over the entire array. The duration of the $S$ wave is a difficult parameter to define. It depends largely on the mechanism of the source and effects of the elastic parameters as they vary along the propagation path. The end of the $S$ wave is set at the time when correlation with distance breaks down and arrivals with other apparent veloci- 
ties are observed. No assumptions are made about the beginning of $S$ except that it is within a reasonable limit (say 20 seconds) from the Jeffreys-Bullen (1940) travel times. In all of the cases, the $S$-wave duration is approximated between 40 and 60 seconds, and this interval plus the preceding noise is used for the array summation techniques.

Noise for purposes here is considered to be of two types: random Gaussian noise with varying degrees of correlation between stations, and coherent arrivals of waves other than the $S$ wave. Microseisms, which are considered to be noise of the first type

TABLE 2

EVENT DATA

\begin{tabular}{|c|c|c|c|c|c|c|c|c|c|}
\hline \multirow{2}{*}{ Case } & \multirow{2}{*}{ Region } & \multirow{2}{*}{ Date } & \multicolumn{3}{|c|}{ Origin Time (GMT) } & \multirow{2}{*}{ Latitude } & \multirow{2}{*}{ Longitude } & \multirow{2}{*}{ Depth, km } & \multirow{2}{*}{ Magnitude } \\
\hline & & & $\mathrm{h}$ & $\mathrm{m}$ & $\mathrm{s}$ & & & & \\
\hline 1 & Kurile Islands & Oct. 3,1965 & 14 & 45 & 26.8 & $49.5^{\circ} \mathrm{N}$ & $156.5^{\circ} \mathrm{E}$ & $30(\mathrm{UPP})$ & 6.2 (UPP) \\
\hline 2 & Kurile Islands & Oct. 24,1965 & 18 & 15 & 04.9 & $49.7^{\circ} \mathrm{N}$ & $156.1^{\circ} \mathrm{E}$ & 30 & 6 (UPP) \\
\hline 3 & Nicaragua & Oct. 20, 1965 & 23 & 54 & 29.9 & $12.5^{\circ} \mathrm{N}$ & $87.4^{\circ} \mathrm{W}$ & 70 & 6.0 (UPP) \\
\hline 4 & $\begin{array}{l}\text { Kirghiz- } \\
\text { Sinkiang }\end{array}$ & Oct. 18,1965 & 10 & 21 & 47.5 & $42.0^{\circ} \mathrm{N}$ & $77.5^{\circ} \mathrm{E}$ & 25 (UPP) & $5.5(\mathrm{UPP})$ \\
\hline 5 & $\begin{array}{l}\text { Novaya } \\
\text { Zemlya }\end{array}$ & Oet. 27,1966 & 05 & 57 & 58.0 & $73.4^{\circ} \mathrm{N}$ & $54.8^{\circ} \mathrm{E}$ & 0 & 6.6 (UPP) \\
\hline 6 & Greece & Oct. 29,1966 & 02 & 39 & 29.4 & $39.2^{\circ} \mathrm{N}$ & $21.2^{\circ} \mathrm{E}$ & 20 & 6.1 (UPP) \\
\hline
\end{tabular}

TABLE 3

Epicentral Distance (Delta) and Azimuth from the Stations

\begin{tabular}{|c|c|c|c|c|c|c|c|c|c|c|}
\hline \multirow{2}{*}{ Case } & \multicolumn{2}{|c|}{ UPP } & \multicolumn{2}{|c|}{ UME } & \multicolumn{2}{|c|}{ NUR } & \multicolumn{2}{|c|}{ KON } & \multicolumn{2}{|c|}{$\mathrm{COP}$} \\
\hline & Delta & Azimuth & Delta & Azimuth & Delta & Azimuth & Delta & Azimuth & Delta & Azimuth \\
\hline 1 & $66.0^{\circ}$ & $28.0^{\circ}$ & $61.9^{\circ}$ & $30.7^{\circ}$ & $63.7^{\circ}$ & $32.8^{\circ}$ & $67.9^{\circ}$ & $22.6^{\circ}$ & $71.0^{\circ}$ & $23.9^{\circ}$ \\
\hline 2 & 65.7 & 28.2 & 61.7 & 30.9 & 63.4 & 33.0 & 67.7 & 22.8 & 70.7 & 24.1 \\
\hline 3 & 86.7 & 289.1 & 86.5 & 291.2 & 89.7 & 295.2 & 82.9 & 282.4 & 85.3 & 285.1 \\
\hline 4 & 40.2 & 88.8 & 39.1 & 96.0 & 36.7 & 95.9 & 44.2 & 82.0 & 43.3 & 80.1 \\
\hline 5 & 19.5 & 31.3 & 15.6 & 37.5 & 17.2 & 29.2 & 21.9 & 33.2 & 24.5 & 27.8 \\
\hline 6 & 20.8 & 172.2 & 24.7 & 178.2 & 21.4 & 187.4 & 21.8 & 155.1 & 17.5 & 156.8 \\
\hline
\end{tabular}

above, are often present in seismic recordings throughout Fennoscandia. For Swedish stations, the microseisms originate mainly along the western coast of Fennoscandia (Bäth, 1949 and Santô, 1962) and can be considered as a random Gaussian process with characteristic directions of propagation (Husebye and Jansson, 1966). Between stations, there can be considerable cross-correlation of microseismic noise with similar periods, and the $s / n$ gain by summation (described later) will be reduced by this effect (Denham, 1963). Coherent arrivals other than the $S$ wave, but with the same apparent velocity, are impossible to suppress with a simple summation technique. However, for distances of about $20^{\circ}-85^{\circ}$ for the shallow events used here, no major waves interfere with the beginning of $S$ except for $P c P$ and $P c S$ which have markedly different apparent velocities from $S$, and $S K S$ which arrives earlier than $S$ beyond $83^{\circ}$. PL may interfere at distances less than $35^{\circ}$ but no evidence for it is seen here. Within the $S$-wave train, major body waves should not interfere up to the $55^{\circ}-85^{\circ}$ epicentral distance interval where $P S, P P S$, and $S c S$ closely follow $S$ at certain dis- 
tances. Shear-coupled $P L$ waves, generally of longer period than $S$, can be expected after the onset of $S V$ with about the same apparent velocity and therefore are difficult to separate from $S V$. Limiting the array analysis to the first part of $S V$ eliminates for all practical purposes the effect of shear-coupled $P L$ on the statistics.

To prepare the original photographic recordings for analysis, the approximate arrival time for $S$ is calculated from the source data (Table 2) and the Jeffreys-Bullen (1940) travel-time tables. Then a four-minute interval with the calculated $S$ time in the center is photographically enlarged six times; distortion from the enlargement is less than the error limits. The enlarged trace is then digitized with an automatic penfollower digitizer and then, to check accuracy, a computer plot of the digitized trace is compared directly with the enlarged trace. The accuracy of the digital data when compared to the original photographic recording is found to be better than $\pm 0.05 \mathrm{~mm}$ or a timing accuracy of \pm 0.2 seconds. Consideration of the time resolution obtainable with long-period records and the minimal response of the instruments above $\frac{1}{2} \mathrm{cps}$ led to the choice of a $\frac{1}{2}$-second digitizing interval which corresponds to a Nyquist or folding frequency of 1 cps.

The $S$-wave arrival is separated by computer rotation into $S H$ and $S V$, which are used for analysis. The vertical component is not used in the axis rotations because it affects only the amplitude of $S V$. To estimate the error of this omission, calculations were made of the percentages of horizontal $S V$ amplitude to total $S V$ amplitude from standard incidence-angle tables for shallow shocks (see for example Ritsema, 1958). The maximum loss of $S V$ amplitude is 20 per cent for the nearest event, with a variation of \pm 7 per cent over the array due to the changing incidence angle. But beyond $37^{\circ}$ source-to-receiver distance, the horizontal traces lose less than 10 per cent of the $S V$ amplitude and vary less than \pm 2 per cent over the longest array dimension. Because the objective is to demonstrate signal coherency across the array irrespective of amplitude variations, which are small in any case, the use of only the horizontal instruments is considered adequate.

Before any array summation is done, the digitized traces are time shifted until the $S$-wave signals are aligned. The shifting is done both by eye and by the cross-correlation of the signals between pairs of stations. Alignment of the signals by eye is found to be quite accurate and satisfactory for most cases.

The types of array processing used here require equal root-mean-square ( $R M S$ ) amplitudes of the time series' noise during the signal interval. Because the noise content of the signal is difficult to separate, an interval immediately preceding the signal is used to calculate noise $R M S$, which is then used to normalize the series. The $R M S$ of the noise is calculated by the relation

$$
n=\left[\frac{1}{m} \sum_{k=1}^{m} A_{k}{ }^{2}\right]^{1 / 2}
$$

where $n$ is the $R M S$ noise level, $m$ is the number of observations, and $A_{k}$ is the amplitude, assuming that the average amplitude is zero. The RMS signal amplitude $s$ is calculated in the same manner using the interval assumed for signal arrival, and the signal-to-noise ratio is $s / n$.

A simple Geneva-type sum of the array time series, which have been properly time shifted for the desired arrival, is one of the methods used. Denham (1963) has shown that, relative to a single seismometer, the $s / n$ improvement using a Geneva-type sum of $k$ seismometers, assuming equal noise power spectra at each site and equal signal 
amplitudes, is

$$
s / n \text { Gain }=\frac{k}{\sqrt{k+\left(k^{2}-k\right) \bar{\rho}}}
$$

where $\rho$ is the average of all the noise correlation coefficients between the stations of the array. If the noise is completely random, then $\tilde{\rho}$ will be zero and from equation (2) the $s / n$ gain becomes $k^{1 / 2}$. Thus, for our array of five stations, the $s / n$ gain in this special case is 2.24. For non-random noise in practical work, Denham concludes that the actual form of the noise spectra is not critically important, and for large component separations, $\bar{\rho}$ is usually less than 0.1 . This is supported by Husebye and Jansson (1966, p. 91), who have calculated the correlation coefficients for the short-period noise in Sweden, and they found that $\bar{\rho}$ varies from -0.03 to +0.07 . If the noise exhibits Denham's maximum $\bar{\rho}$ of 0.1 , the gain from equation (2) is 1.89. Thus, assuming Denham's noise model of equal noise power and equal signal amplitudes, a sum of the outputs from five stations should achieve $s / n$ gains between 1.89 and 2.24.

Commonly-used array techniques in seismology are based on the assumption that the signal amplitudes are equal for all time series (see for example Kelly and Levin, 1964). In array applications it has been noted that this is not true (Capon, Greenfield and Lacoss, 1966), and the performance of array techniques based on this assumption is therefore impaired. In practice, the level of both the signal and noise are important because it is the $s / n$ ratio which is of greatest interest. For example, it has been noted (VESIAC, 1962, p. 26 and p. 102) that, although granite seismometer bases usually have lower absolute noise levels than bases of limestone or basalt, the increased signal levels of the latter often produce higher $s / n$ ratios. Christoffersson and Jansson (1967) have developed a maximum likelihood method that estimates the signal amplitudes together with the signal, thus providing a technique to account for large differences of noise variance and signal amplitude between the widespread stations of the array. For a simplified description of the method, assume that $m$ seismic time series of length $n$ are represented by $X_{i j}$ where $i=1,2, \cdots, n$ and $j=1,2, \cdots, m$. If the series are multiplied by a weighting factor $W_{j}$ and summed, the result is

$$
Q_{i}=\frac{1}{m} \sum_{j=1}^{m} W_{j} X_{i j} \quad i=1,2, \cdots, n
$$

Now, a residual $R$ is defined as

$$
R=\sum_{j=1}^{m} \sum_{i=1}^{n}\left(X_{i j}-Q_{i}\right)^{2}
$$

Using least-squares estimation methods, Christoffersson and Jansson find a set of weights $W_{j}$ which minimize the residual $R$ and make the weighted sum $Q_{i}$ the best estimate of the common signal. Thus, a time series with a low $s / n$ ratio or with a distorted signal is weighted the least because it has less in common with the remaining time series.

\section{Results}

Case 1. This earthquake from the Kurile Islands has the highest $s / n$ ratio of the cases studied. It is therefore a good example for the study of correlation across the 
array with minimal interference from noise. Figures 3 (a) and 3 (b) show the digitized traces representing $S V$ and $S H$, respectively, with the five individual traces above and the direct sums and weighted sums below. The traces are normalized to their maximum amplitudes for convenient illustration. A trace directionality convention was adopted for an observer looking from the event to the station as follows: $S V$ - up on the trace indicates motion towards the station and down; $S H-$ up on the trace indi-
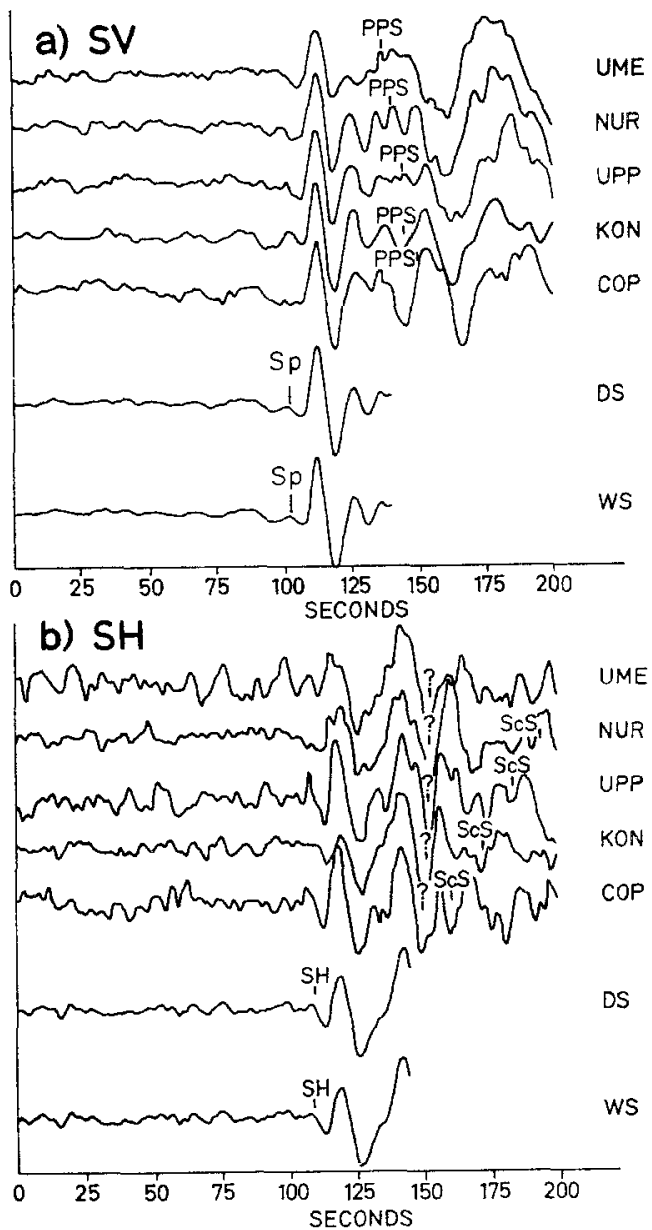

Fig. 3. (a) $S V$ from the Kurile Islands event on October 3, 1965. Amplitudes are normalized by the maximum value. $P P S$ and $S c S$ marks are from Jeffreys-Bullen table (1940). $D S=$ direct sum. $W S=$ weighted sum. (b) $S H$ from the Kurile Islands event on October 3, 1965. Amplitudes are normalized by the maximum value.

cates motion to the left of the station. The statistics of $S V$ and $S H$ are computed using a 40-second interval of the signal. Power spectra and selected cross-correlation and coherency functions for $S V$ and $S H$ are shown in Figures 4 (a) and 4 (b), respectively. The $S V$ set of traces is used to compute alignment of both the $S V$ and SH signals, and the cross-correlations in Figure 4 confirm alignment by showing maxima at zero phase shift. The signal frequency of about $\frac{1}{14} \operatorname{cps}$ dominates the power spectra diagrams in Figure 4 as expected. The high visual correlation of the $S V$ series in Figure $3(\mathrm{a})$ is confirmed by the high cross-correlation of 0.9 to almost 1.0 and 
a) POWER SPECTRA(SY
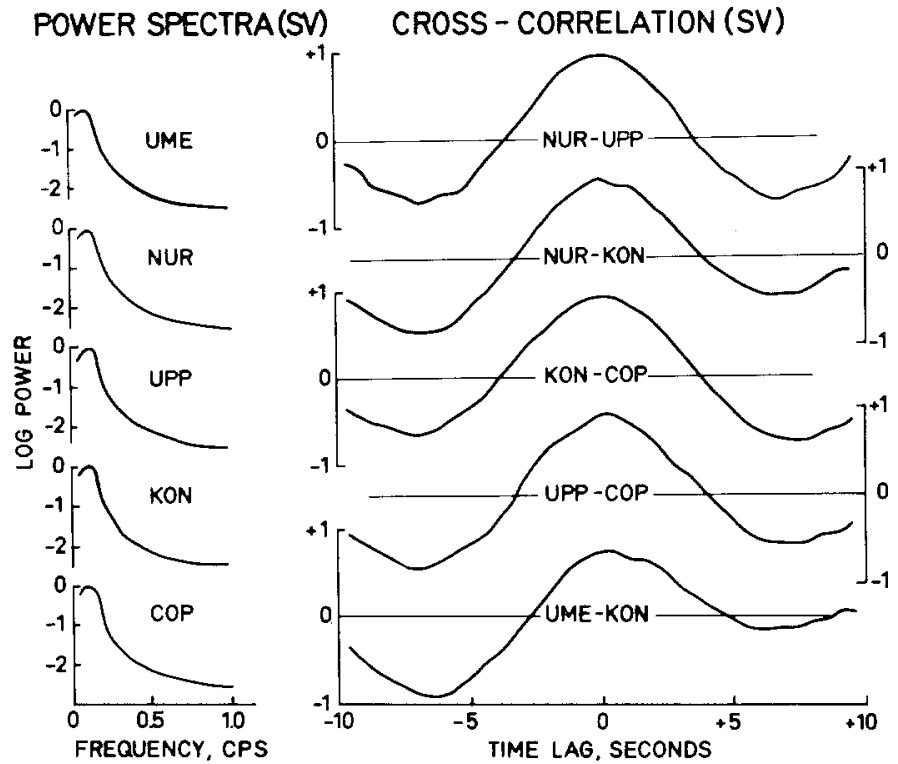

COHERENCY (SV)

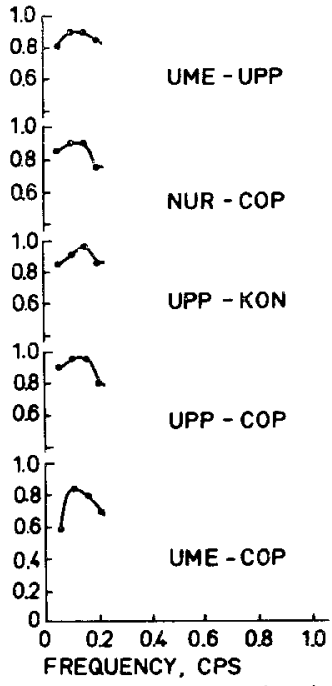

b)

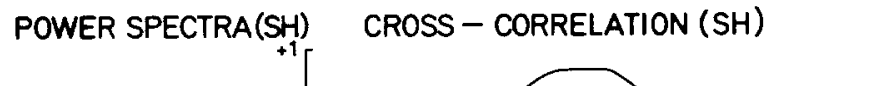

COHERENCY (SH)

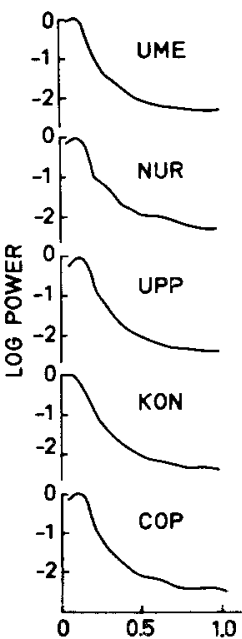

FREQUENCY, CPS
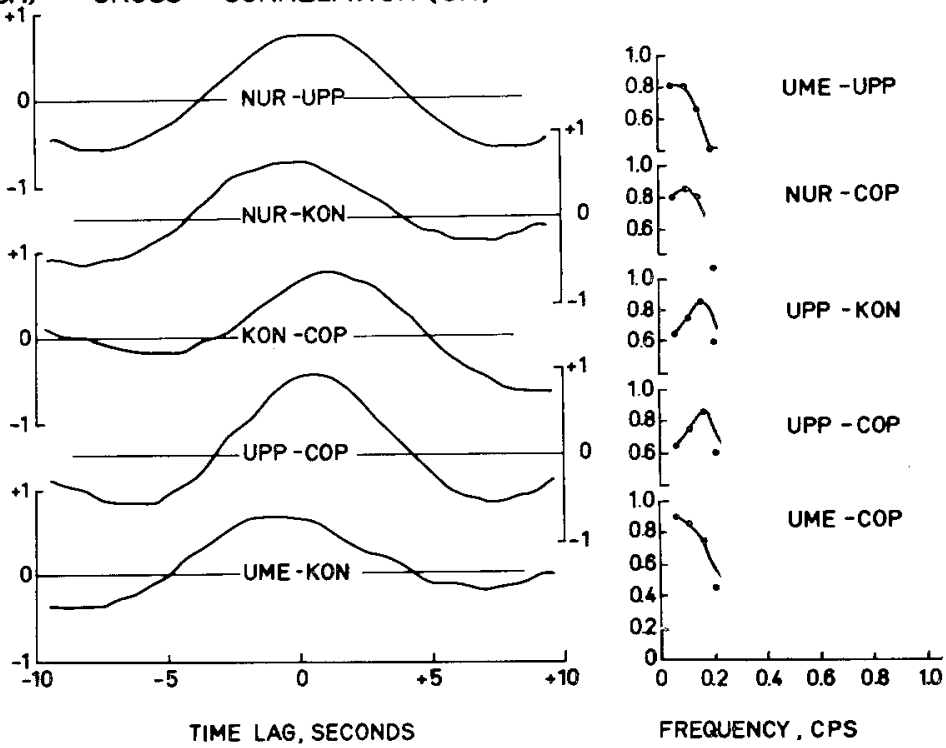

Fig. 4. (a) SV signal power spectra, selected cross-correlations, and coherencies for the Kurile Islands event on October 3,1965 . Spectra are normalized by the maximum value. (b) $S H$ signal power spectra, selected cross-correlations, and coherencies for the Kurile Islands event on October 3,1965 . Spectra are normalized by the maximum value.

similar values of coherency for the dominant signal frequencies (only those frequencies with significant power are shown in the coherency plots). Phase lags are very small and give little additional information. The statistics of $S H$, although influenced by a lower $s / n$ ratio observable in Figure 3 (b), also show high correlation between the series of the array (Figure 4 (b)). $S H$ shows a frequency of about $\frac{1}{16} \mathrm{cps}$, and the power spectra of Figure 4 (b) show a higher noise content in the signal. Cross-correlation and coherency in Figure 4 (b) show values of 0.70 to 0.95 for the dominant signal 
frequencies. However, cross-correlations between $\mathrm{KON}$ and the other stations for $S H$ are not maximum at zero phase shift, thus disagreeing with the alignment of $S V$; this delay of $S H$, about one second, is observable by eye in Figure 3 (b). It is believed that a real $S H$ velocity decrease somewhere along the travel path to KON causes the delay, because for both $S H$ and $S V$, later arrivals are observed which show consistent time move-outs with the current alignment of the traces.

TABLE 4

Weights $W_{j}$ For Forming the Weighted Sum

\begin{tabular}{|c|c|c|c|c|c|}
\hline Case & UPP & UME & NUR & KON & $\mathrm{COP}$ \\
\hline \multicolumn{6}{|l|}{1.} \\
\hline$S V$ & 0.351 & 0.268 & 0.444 & 0.614 & 0.480 \\
\hline$S H$ & 0.395 & 0.323 & 0.495 & 0.591 & 0.380 \\
\hline \multicolumn{6}{|l|}{2} \\
\hline$S V$ & 0.426 & 0.179 & 0.299 & 0.773 & 0.314 \\
\hline$S H$ & 0.892 & 0.316 & 0.234 & 0.206 & -0.079 \\
\hline \multicolumn{6}{|l|}{3} \\
\hline$S V$ & 0.433 & 0.443 & 0.678 & 0.345 & 0.195 \\
\hline$S H$ & 0.034 & 0.839 & 0.466 & 0.269 & 0.068 \\
\hline$S V$ (FIL) & 0.468 & 0.437 & 0.541 & 0.246 & 0.487 \\
\hline \multicolumn{6}{|l|}{4} \\
\hline$S V$ & 0.412 & 0.370 & 0.716 & 0.345 & 0.246 \\
\hline$S H$ & -0.811 & -0.026 & 0.044 & 0.349 & 0.467 \\
\hline$S V$ (FIL) & 0.053 & 0.204 & 0.921 & 0.319 & 0.082 \\
\hline$S H(\mathrm{FL})$ & -0.097 & 0.251 & 0.470 & 0.839 & 0.053 \\
\hline \multicolumn{6}{|l|}{5} \\
\hline$S V$ & -0.685 & -0.205 & -0.255 & 0.649 & 0.128 \\
\hline$S H$ & -0.092 & -0.407 & 0.901 & 0.089 & -0.789 \\
\hline \multicolumn{6}{|r|}{0.100} \\
\hline$S V$ & -0.027 & 0.077 & -0.101 & 0.991 & 0.019 \\
\hline$S H$ & 0.359 & 0.261 & 0.741 & 0.503 & -0.019 \\
\hline
\end{tabular}

The direct and weighted sums for $S V$ and $S H$ are shown in Figures 3 (a) and 3 (b), respectively. The weights $W_{j}$ from formula (3) which are multiplied with the individual series to make the weighted sum are given in Table 4 . The large signal amplitudes and high correlation between the individual series cause the $W_{j}$ values to be relatively equal, and the wave shape of the weighted sum is not visibly different from the shape of the direct sum. Values of $s / n$ gain for the two types of summation processes are given in Table 5 , and it is seen that the weighted sum of $S V$ produces a small increase of 7.7 per cent in $s / n$ gain over the direct sum.

Times are read for $S V$ and $S H$ on the summed traces in Figures 3 (a) and 3 (b), respectively. These times, together with the Jeffreys-Bullen (1940) table residuals (residual $=$ read time minus $J-B$ time), are given in Table 6 . For comparison, the $P$-wave arrival times and their residuals are also given. The times for $S H$ give much smaller residuals than those for $S V$, and the $S H$ residuals are directly comparable within accuracy limits to those of $P$. That is, the $S H$ residual is approximately twice the $P$ residual, reflecting the velocity relation between the two wave types. Thus, the $S H$ probably gives the true $S$ time, but the early $S V$ reading on the first down-break 
of the trace is believed to be signal because of its correlation between the traces and its similarity to the $S V$ signal in Case 2.

The early $S V$ reading was studied by Băth and Stefánsson (1966), who showed that the six-second earlier $S V$ at Swedish stations was really $S p$, an $S V$-to- $P$ conversion at the crustal boundary in the Fennoscandian region. Analysis of the particle motion shows that the first motion of the in-line signal is in the $P$ direction as shown for UPP in Figure 5. The $P$-type motion gradually converts to $S V$-type motion by the time of the $S H$ onset on the transverse trace. This $S V$ motion before $S H$ onset is interpreted

TABLE 5

$s / n$ GAINS

\begin{tabular}{|c|c|c|c|}
\hline case & Direct Sum & Weighted Sum & Increase Per Cent \\
\hline \multicolumn{4}{|l|}{1} \\
\hline$S V$ & 2.08 & 2.24 & 7.7 \\
\hline$S H$ & 2.04 & 2.01 & -1.5 \\
\hline \multicolumn{4}{|l|}{2} \\
\hline$S V$ & 2.00 & 2.48 & 24.0 \\
\hline$S H$ & 1.76 & 2.25 & 27.8 \\
\hline \multicolumn{4}{|l|}{3} \\
\hline$S V$ & 1.77 & 1.76 & -0.6 \\
\hline$S H$ & 1.35 & 1.55 & 14.8 \\
\hline$S V($ FIL $)$ & 1.65 & 1.76 & 6.7 \\
\hline \multicolumn{4}{|l|}{4} \\
\hline$S V$ & 2.08 & 1.93 & -7.2 \\
\hline$S H$ & 0.91 & 1.23 & 35.2 \\
\hline$S V$ (FIL) & 1.57 & 2.28 & 45.2 \\
\hline$S H$ (FIL) & 1.10 & 1.64 & 49.1 \\
\hline \multicolumn{4}{|l|}{5} \\
\hline$S V$ & 1.13 & 1.44 & 27.4 \\
\hline$S H$ & 0.98 & 1.49 & 52.0 \\
\hline \multicolumn{4}{|l|}{6} \\
\hline$S V$ & 1.57 & 2.60 & 65.6 \\
\hline$S H$ & 1.99 & 2.24 & 12.6 \\
\hline
\end{tabular}

to be a reverse conversion of $S p$ back to $S V$ as a complicated function of wavelength and detailed layering in the crust. It is apparent, however, that the onset time of the first $S p$ arrival is a function only of the depth of the first conversion interface and the average $P$ velocity above it.

Three arrivals are visible after the $S$ wave, but are not analyzed in detail here. After $S V$, a long-period wave appears that is probably PPS. Jeffreys-Bullen (1940) table times of $P P S$ are marked in Figure 3 (a). A distinct wave is seen approximately 30 to 40 seconds after $S H$ with a slightly higher apparent velocity. This arrival does not correspond to any of the major waves and is indicated with a question mark in Figure 3 (a). In the same figure, times from the Jeffreys-Bullen tables for ScS are marked and a small wave corresponds with these marks at UPP, KON, and COP. All of these arrivals appear to correlate visually from station to station.

Case 2. The focus for this earthquake from the Kurile Islands is in an almost identical position to that of Case 1 (see Table 2). However, the event is of a lower magnitude and shows smaller trace amplitudes at the array stations. The original long-period 


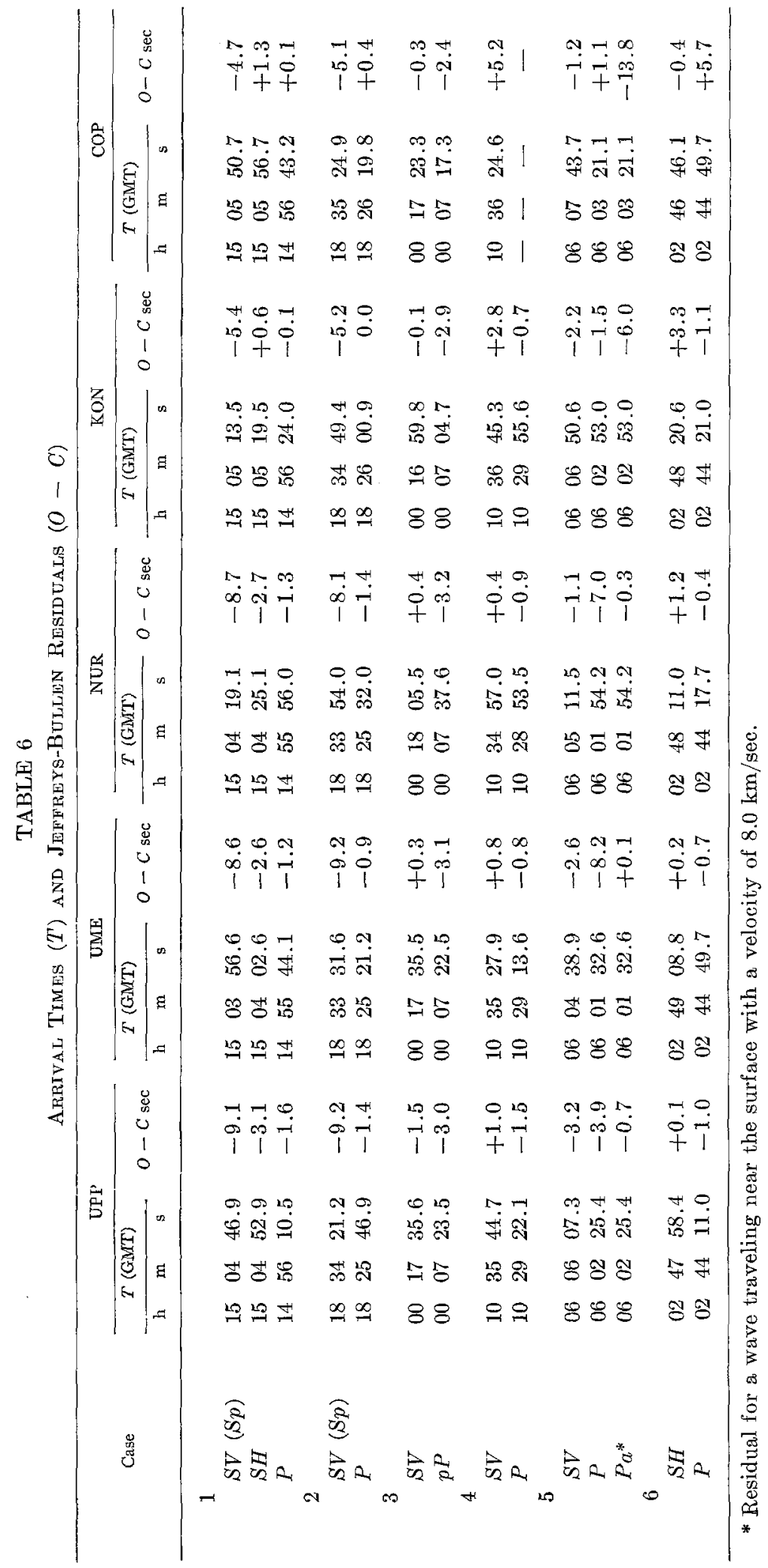


horizontal recordings in Figure 6 show the small amplitudes of $S$. This earthquake is used as a comparison to Case 1 and as a classical test of the array's ability to improve the $s / n$ ratio of a weak signal immersed in a noise background. $S V$ and $S H$ of the digitized and time-shifted traces are shown in Figures 7 (a) and 7 (b), respectively.

The statistical functions of the $S V$ signal are shown in Figure 8. Cross-correlations are lower for $S V$ compared to Case 1, but the coherency is high and ranges from 0.80

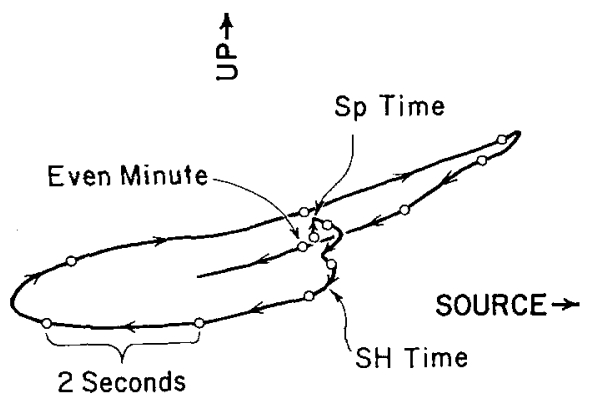

FIG. 5. Particle motion of the October 3,1965 , Kurile Islands event at UPP in the $S V-P$ plane.

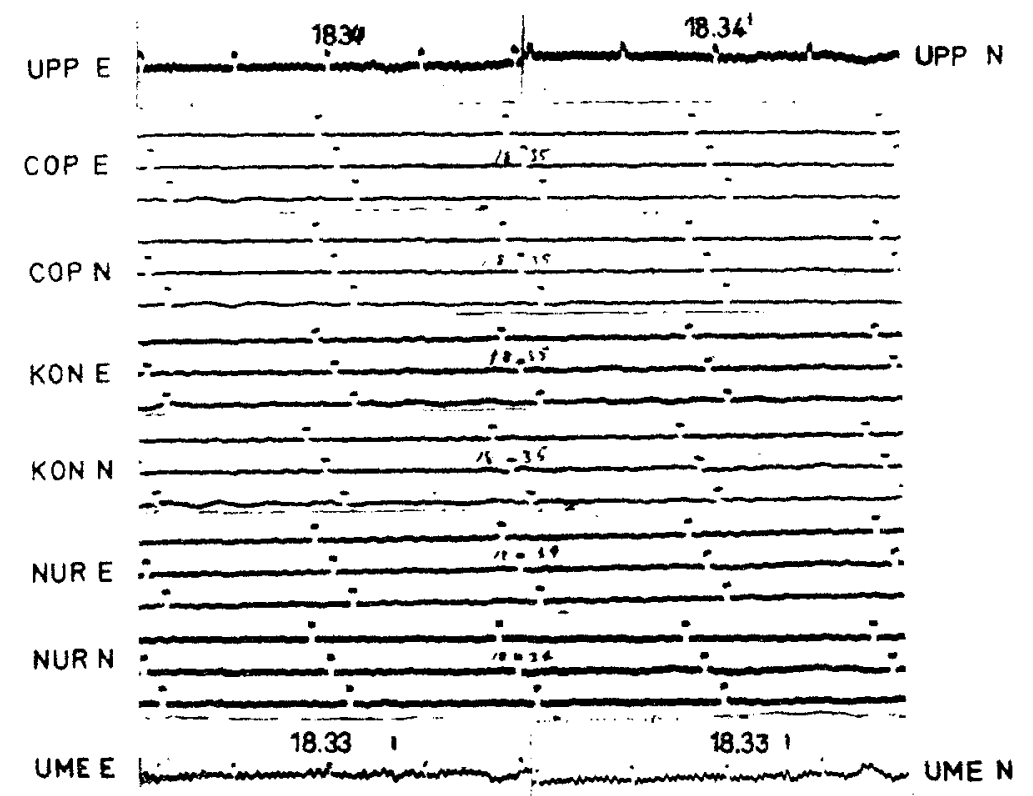

FIG. 6. Original recordings for the October 24, 1965, Kurile Islands event.

to 0.95 for the dominant $S V$ signal frequencies seen in the power spectra curves. $S H$ statistics are not shown, but the coherency is lower in general and shows the highest values between UPP and all other stations except COP, which explains why UPP was weighted with the highest and COP with a negative value of $W_{j}$ (see Table 4) for the weighted sum in Figure 7 (b). Phase lags (not shown) are small for the $S V$ signal frequencies and large, as expected, for $S H$ signal frequencies.

The weighted $S V$ sum compared to the direct sum in Figure 7 (a) gives an improvement in $s / n$ gain of 24 per cent, as seen in Table 5 . The $S V$ signal of the direct and weighted sums is much more readable than $S V$ on the individual traces, except per- 
haps in KON. In $\mathrm{KON}$, however, the beginning of the $S V$ wave might be difficult to read, especially if the original recordings of Figure 6 are used.

It is interesting to compare the shape of $S V$ with that of Case 1 . The wave shapes are identical except that the amplitude of the first down-break in Case 1 is smaller. The beginning of this down-break in both Case 1 and Case 2 is read as the $S V p$ arrival

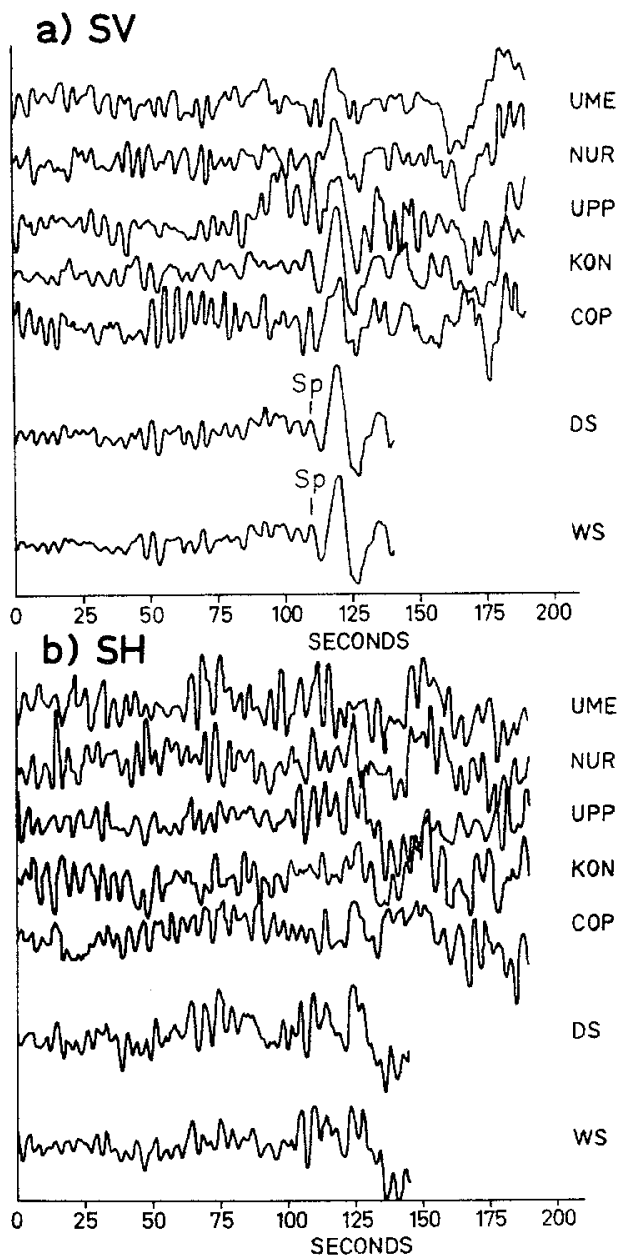

FIG. 7. (a) $S V$ from the Kurile Islands event on October 24, 1965. Amplitudes are normalized by the maximum value. (b) $S H$ from the Kurile Islands event on October 24, 1965. Amplitudes are normalized by the maximum value.

given in Table 6 . The residuals (Table 6 ) of these $S V p$ times for Cases 1 and 2 are identical for all stations within the error limits, and the agreement gives confidence to the time readings of both cases. Poor correlation between stations obscures the beginning of $\mathrm{SH}$ and no time is read.

Case 3. This event is the most distant and the deepest of the cases and originates in Nicaragua (Table 2). The array is located at a distance $83^{\circ}-90^{\circ}$ (see Table 3), where $S K S$ emerges and precedes $S$ in time as distance increases. The $S V$ and $S H$ traces shown in Figures 9 (a) and 9 (b) demonstrate a complexity resulting from interfering wave patterns of $S$ and $S K S$. Because of this problem, an even band-pass filter from $\frac{1}{25}$ to $\frac{1}{15} \mathrm{cps}$ is used on the individual traces to clarify the signals and determine the 
best time shift for summing. The filtered traces in Figure 10 show considerable improvement, and the resulting sums in both Figures 9 (a) and 10 permit a distinct reading of $S V$. Residuals from this $S V$ reading are small and consistent (see Table 6 ). The first motion from the event arrives too late for $P(+16$ seconds), but its time agrees fairly well with that calculated for $p P$ (Table 6) using the USCGS depth of $70 \mathrm{~km}$ (see Table 2). The relatively large $p P$ residuals in Table 6 suggest that the depth may be shallower than $70 \mathrm{~km}$.

Little improvement in $s / n$ gain (Table 5 ) is made by the weighted-sum compared to the direct-sum method on $S V$, an indication that $s / n$ ratios for all the traces are roughly equivalent. $s / n$ equivalence is also suggested by the relative equality of the
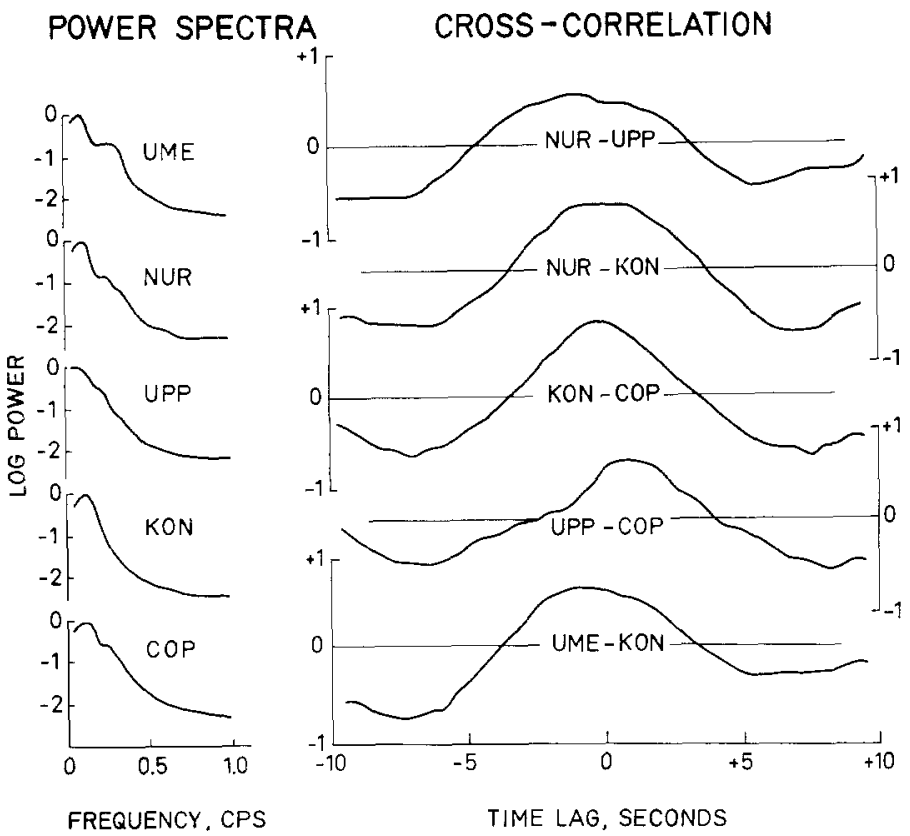

\section{COHERENCY}

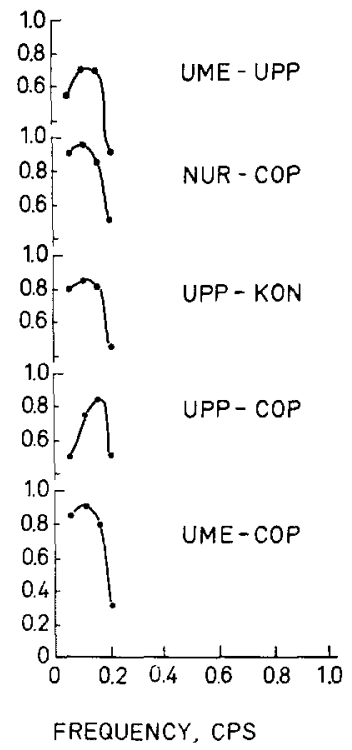

FIG. 8. SV signal power spectra, selected cross-correlations, and coherencies for the Kurile Islands event on October 24, 1965. Spectra are normalized by the maximum value.

weights $W_{j}$ for $S V$ in Table 4. Both the normal and filtered (not shown) $S H$ sums in figures 9 (a) and 10 fail to show any significant improvement in the signal. Statistics computed for $S V$ and $S H$ show a high correlation and coherency $(0.85$ to 0.95$)$ of the $S V$ signal between UPP, UME, and COP and fair correlation of $S H$ signal between UPP, UME, and NUR.

A distinctive feature of Figure 10 is the move-out of $S K S$ which arrives earlier than $S$ with a higher apparent velocity. $S K S$ times from the Jeffreys-Bullen (1940) table are marked on Figure 10; they coincide with $S$ at KON and agree well with the large signal arriving earlier than $S$ at increasing distances. $S K S$ is suppressed in the sums for $S V$ (figures 9 (a) and 10 ), but $S K S$ appears to correlate well across the array and could be processed in the same manner as $S$.

Case 4. In this example the array is at a distance interval that includes the intersection point of $S-P C S$ from the earthquake originating at Kirghiz-Sinkiang (see Tables 2 and 3 ). Because of possible complications from the intersection and the low $s / n$ ratio of the $S V$ and $S H$ traces shown in Figures 11 (a) and 11 (b), band-pass filtering 
of $\frac{1}{40}$ to $\frac{1}{15} \mathrm{cps}$ for $S V$ and $\frac{1}{25}$ to $\frac{1}{15} \mathrm{cps}$ for $S H$ is again used to clarify the signals for calculation of time shifts. The filtered $S V$ and $S H$ traces are shown in Figures 12 (a) and 12 (b), respectively, and the direct and weighted sums for both filtered and non-filtered traces are shown in Figures 11 (a), 11 (b), 12 (a), and 12 (b). A

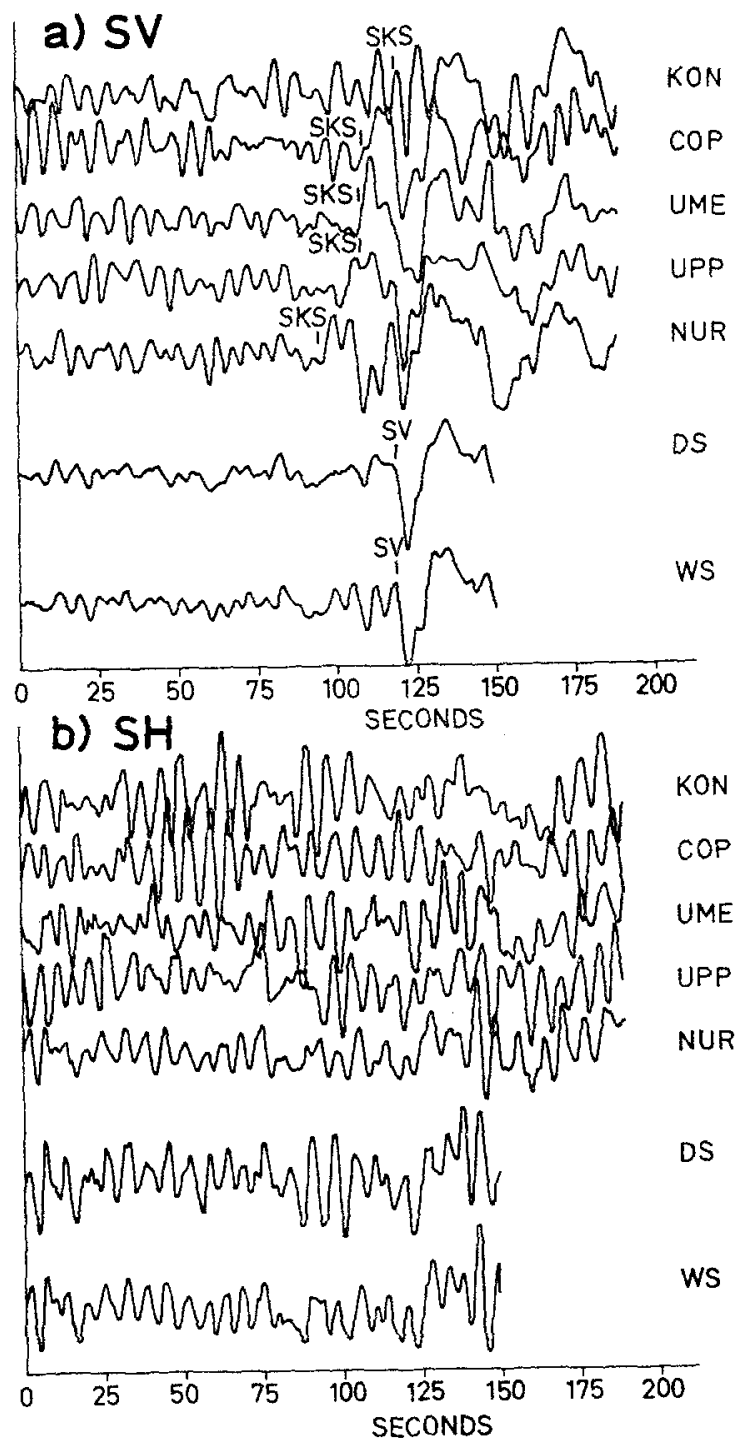

F1G. 9. (a) SV from the Nicaragua event on October 20, 1965. Amplitudes are normalized by the maximum value. $S K S$ marks are from Jeffreys-Bullen (1940) table. (b) $S H$ from the Nicaragua event on October 20,1965 . Amplitudes are normalized by the maximum value.

distinct $S V$ signal appears in the filtered summations of Figure 12 (a) and a less distinct $S H$ signal is visible in Figure 12 (b). Computed statistics show good coherency $(0.80$ to 0.90$)$ of the $S V$ signal between all stations except COP and fair coherency ( 0.54 to 0.64 ) of the $S H$ signal between NUR, UME, and KON. The coherency computations agree with the weights in Table 4 computed for the filtered traces of $S V$ and $S H$; that is, $S V$ in COP and $S H$ in UPP and COP are weighted low because of low correlation. The $s / n$ gain improvements of the weighted sum com- 
pared to the direct sum on filtered $S V$ and $S H$ are near 50 per cent (Table 5 ), a further indication of varying $s / n$ ratios and correlation between stations.

Although fair-to-good correlation of $S V$ is seen on all traces except COP, the beginning large motion of the summed signals results in an $S V$ residual of about +15 seconds (Figure 12 (a)). Since no good earlier arrival is seen on the summed signals, KON, which shows an earlier motion near the proper time, is used for reading the beginning of $S V$. The reading results in small residuals except at $\mathrm{KON}(+2.8$ seconds $)$ and COP ( +5.2 seconds) in Table 6 . The reading of absolute $S V$ arrival time from only one station does not give as much confidence as the times in the previous cases. However, correlation of the latter part of $S V$ gives information about the apparent

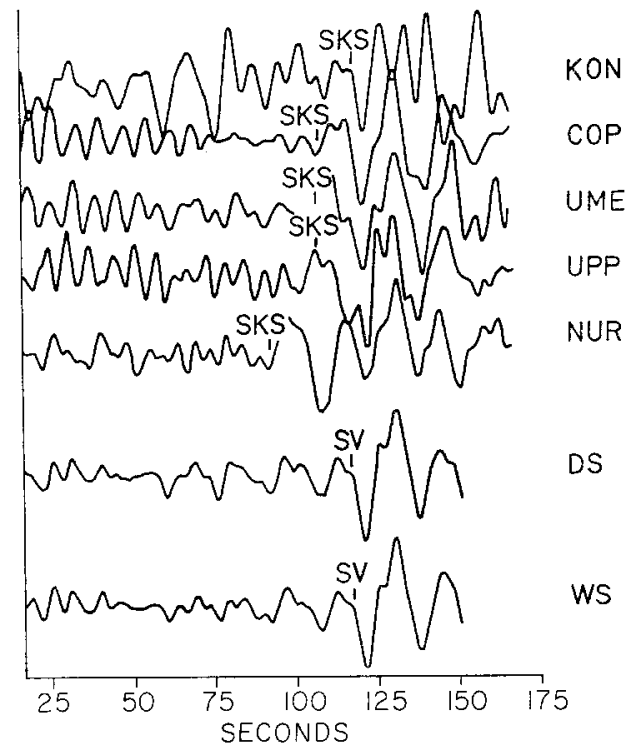

FIg. 10. Filtered $S V$ (band-pass of $\frac{1}{25}$ to $\frac{1}{15} \mathrm{cps}$ ) from the Nicaragua event on October 20 , 1965. Amplitudes are normalized by the maximum value. $S K S$ marks are from Jeffreys-Bullen (1940) table.

velocity which is not dependent on absolute times. $S H$ (Figure 12 (b)) has some correlation, but again, the beginning of $S H$ is difficult to see and no times are read.

According to the Jeffreys-Bullen (1940) tables, the $P c S$ arrival should coincide with $S V$ near the distance of UPP and COP. Although no PcS is visible in Figures 11 (a) and 12 (a), the low $S V$ signal correlation of COP could be related to interference from $P c S$.

Case 5. This event, an underground nuclear test at Novaya Zemlya, is at a position where the array is across the $20^{\circ}$ travel-time complication and shows very little correlation across the array (Figures 13 (a) and 13 (b)). In addition, the event itself appears complicated because of large $S H$ amplitudes. The $S V$ traces are aligned by a large down-break after the time $S V$ should arrive, and $S V$ and $S H$ signals are summed using this time shift. Because $S$ almost vanishes between the distances of $12^{\circ}-18^{\circ}$, an $S$ signal is not expected until the distance of UPP. The $S V$ beginning is read as marked on the direct sum trace in Figure 13 (a) and coincides fairly well with the beginning of $S V$ on UPP, KON, and COP. Residuals are between -3.2 to -1.1 seconds (Table 6 ). Although significant signal energies are seen in the $S H$ orientation (Figure 13 (b)), correlation is poor and no times are read.

The Press-Ewing long-period seismometer records from COP were unavailable for 
this case, and recordings from COP's Galitzin-Wilip horizontal seismometers $\left(T_{0}=\right.$ $12.5 \mathrm{sec}, T_{g}=12.5 \mathrm{sec}$ ) were used in their place for illustration. However, due to the low signal correlation for the other stations in this case, corrections were not made for the Galitzin-Wilip characteristics.

The $P$-wave residuals are quite large for stations UPP, UME, and NUR (Table 6 ) using Jeffreys-Bullen (1940) times. However, comparison to times for $\mathrm{Pa}$ (observed

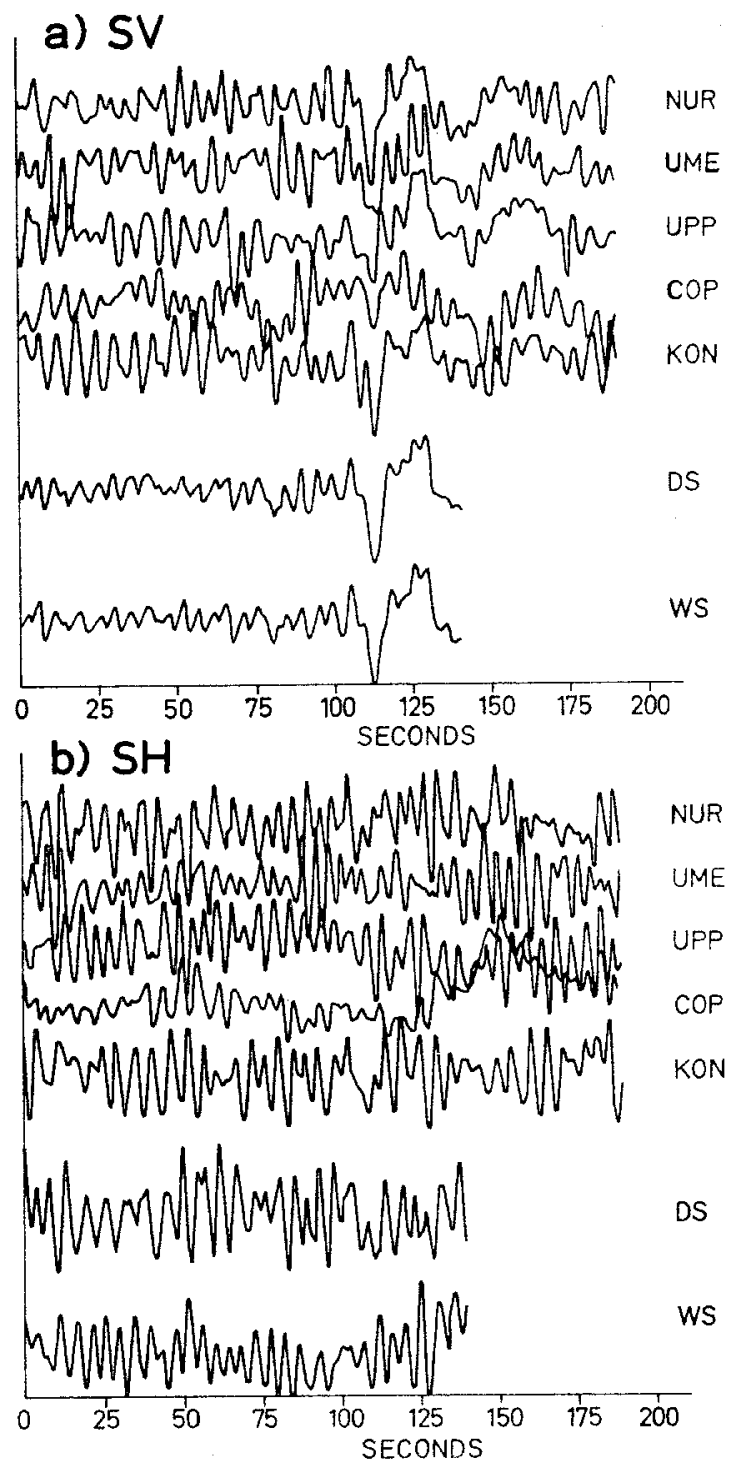

FIg. 11. (a) $S V$ from the Kirghiz-Sinkiang event on October 18, 1965. Amplitudes are normalized to the maximum value. (b) SH from the Kirghiz-Sinkiang event on October 18, 1965. Amplitudes are normalized to the maximum value.

by Båth and Arroyo, 1963) traveling with an apparent surface group velocity of 8.0 $\mathrm{km} /$ sec results in very small residuals for these three stations. Thus, the first arrival at UPP, UME, and NUR is probably $P a$ and the first arrival at KON and COP is $P$.

Case 6. Array distances to this earthquake in Greece are also near $20^{\circ}$, where $S$ starts to reappear after almost vanishing in the interval $12^{\circ}$ to about $18^{\circ}$. COP is the nearest 
station at a distance of $17.5^{\circ}$ (Table 3 ). The $S V$ and $S H$ traces in Figures 14 (a) and 14 (b) show that the beginning of $S$ at COP is small compared to the other stations. For this earthquake, the $S H$ gives a definite break on all traces except COP, and this reading is used for the time shifts of the traces. Statistical calculations of both $S V$ and $S H$ show high signal correlation and coherency ( 0.80 to 0.95$)$ between UPP and NUR and fair-to-low signal correlation and coherency for the remaining combinations. This is explained by the complications of the $S$ travel-time curve near $20^{\circ}$ (Jeffreys and
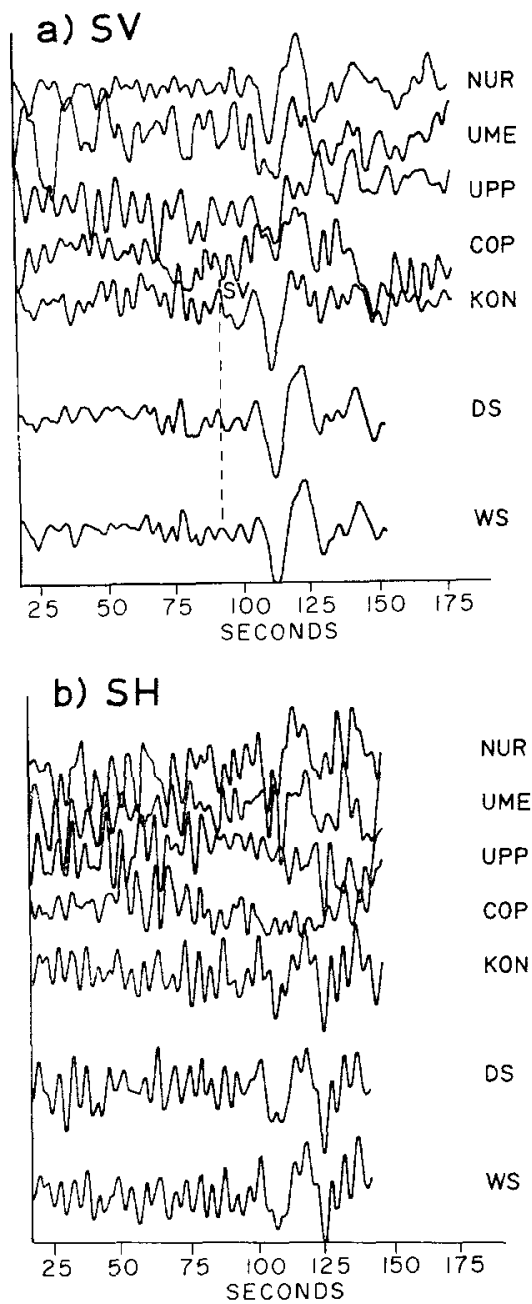

FIG. 12. (a) Filtered $S V$ (band-pass of $\frac{1}{40}$ to $\frac{1}{15} \mathrm{cps}$ ) from the Kirghiz-Sinkiang event on October 18, 1965. Amplitudes are normalized by the maximum value. (b) Filtered $S H$ (band-pass of $\frac{1}{2}$ to $\frac{1}{15} \mathrm{cps}$ ) from the Kirghiz-Sinkiang event on October 18, 1965. Amplitudes are normalized by the maximum value.

Bullen, 1940); that is, two branches of the curve intersect between NUR and KON so that the beginning $S V$ and $S H$ arrivals at KON and UME are complicated by superposition of waves. The Jeffreys-Bullen tables give times for the earlier arriving wave of the two branches. The Jeffreys-Bullen residuals of the $S H$ times read from Figure 14 (b) are small (see Table 6 ), except for +3.3 at KON. In the $S V$ summed traces of Figure 14 (a), the indicated first motion is approximately five seconds earlier than $S H$, similar to the difference noted in Case 1. But, low correlation of the $S V$ in Figure 14 (a) gives less confidence to interpretation of the summed traces. 


\section{Discussion}

The primary objective of this paper is to demonstrate correlation of the signals across the array. Case 1 has the highest $s / n$ ratio of the cases studied and, therefore, the statistics of the signal are the most dependable. Cross-correlation and coherency computations (shown in Figures 4 (a) and 4 (b)) demonstrate values between 0.90

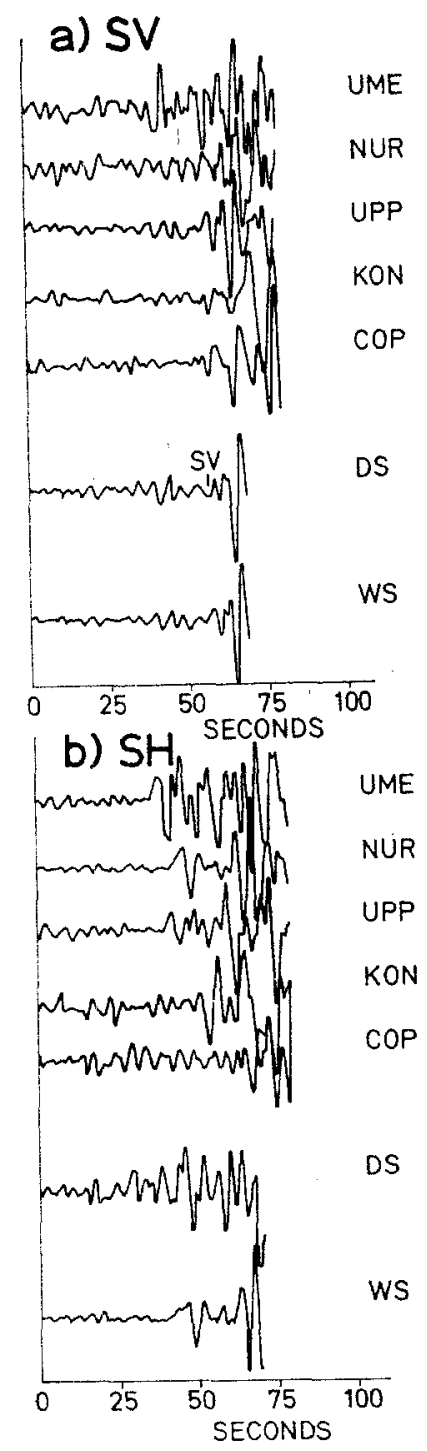

Fig. 13. (a) $S V$ from the Novaya Zemlya event on October 27, 1966. Amplitudes are normalized by the maximum value. (b) $S H$ from the Novaya Zemlya event on October 27, 1966. Amplitudes are normalized by the maximum value.

and 1.00 for the array signals of Case 1. Case 2 statistical computations on $S V$, although somewhat less dependable because of higher noise content of the signal, also show high cross-correlation and coherency values of 0.80 to 0.95 for the signal frequencies. In Case 3 and Case 4 , high cross-correlation and coherency values between 0.80 and 0.95 are observed on $S V$ between most of the stations, even though the signal is highly distorted by noise and other waves arriving at the same time. The above signal statisties confirm high correlation of the $S$-wave signal and justify the 
use of array-summation methods on long-period $S$ waves beyond $30^{\circ}$ source distance. Waves other than $S$ are noted in Cases 1,3 , and 4 , and these arrivals visually correlate between stations. Thus, array techniques can probably be applied with equal success to other long-period arrivals.

Cases 5 and 6 cause much more difficulty when trying to correlate signals across the array. This is due to their distance from the epicenter, near $20^{\circ}$, where discontinuity

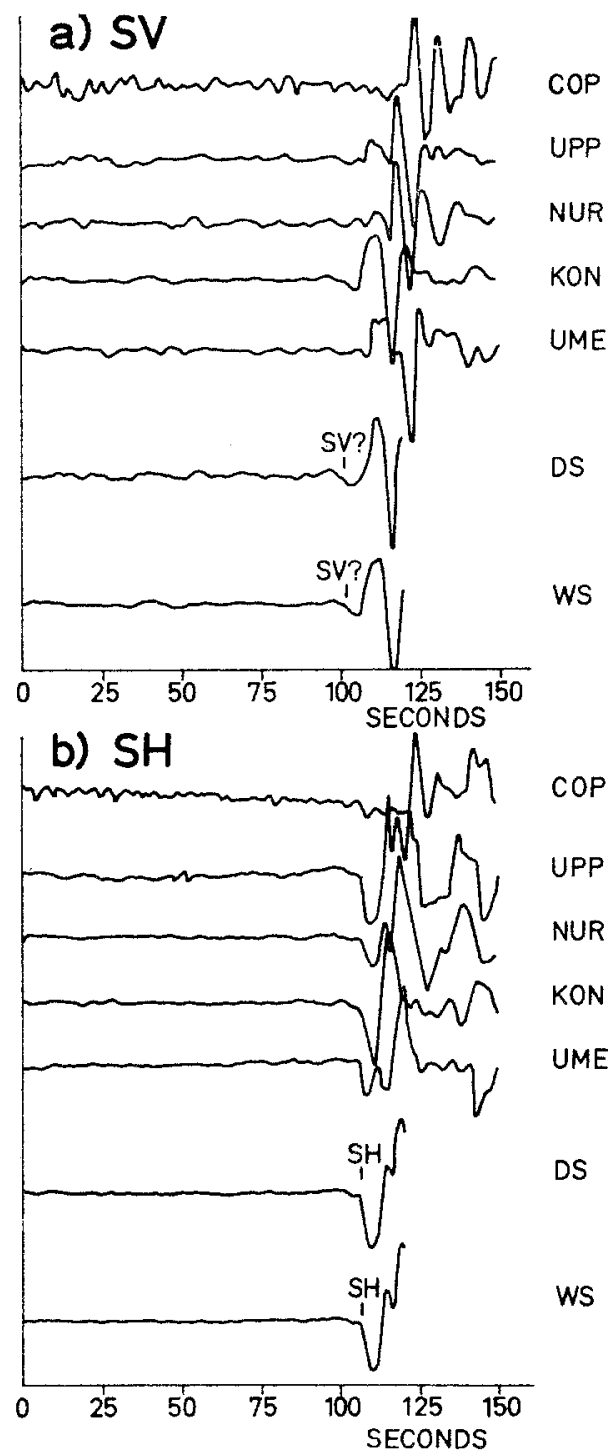

FIG. 14. (a) $S V$ from the Greece event on October 29, 1966. Amplitudes are normalized by the maximum value. (b) $S H$ from the Greece event on October 29, 1966. Amplitudes are normalized by the maximum value.

effects at depth complicate the $S$-wave arrivals. The $S$-wave signal changes rapidly over the relatively large aperture of the array, which is almost one-half $\left(9^{\circ}\right)$ of the epicenter-to-station distances. $30^{\circ}$ epicenter-to-station distance is considered to be a lower limit for the use of this array for summation. However, for shorter distances, a simple separation of original recordings into $S V$ and $S H$ and direct comparison of the array traces are helpful for interpretation, such as clarification of the $S H$ waves in Case 6. 
For cases with good signal correlation, the array-summation methods give an $s / n$ gain that is fairly consistent with the prediction of 1.89 to 2.24 . Values lower than 1.89 can be attributed to higher correlation of the noise than is assumed or to inaccuracies in the method used to compute $s / n$, which cannot measure the noise content of the signal. The weighted-sum method gives a marked improvement in $s / n$ gain for Case 2 and the filtered traces of Case 4 (see Table 5 ).

Some potential sources of $S$-wave residual scatter are seen. Case 1 , Case 2, and perhaps Case 6 show examples of the $S p$ wave ( $S V$-to- $P$ conversion at the base of the crust) arriving 5-6 seconds before $S V$ and $S H$. The results here indicate that $S p$ is not rare, but since the common practice is to report the earliest $S$ reading, $S p$ can be often misread as $S$ if only unprocessed original records are used. $S p$ is separated from $S H$ only when the source azimuth happens to be in line with one of the horizontal instruments or when the components are oriented towards the source, as done here.

TABLE 7

Jeffreys-Bullen Residuals Minus the Average Residual for Each Case

\begin{tabular}{cccccc}
\hline Case & UPP & UME & NUR & KON & COP \\
\hline 1 & -1.8 & -1.3 & -1.4 & +1.9 & +2.6 \\
2 & -1.8 & -1.8 & -0.7 & +2.2 & +2.3 \\
3 & -1.3 & +0.5 & +0.6 & +0.1 & -0.1 \\
4 & -1.0 & -1.2 & -1.6 & +0.8 & +3.2 \\
5 & -1.1 & -0.5 & +1.0 & -0.1 & +0.9 \\
6 & -0.8 & -0.7 & +0.3 & +2.4 & -1.3 \\
\hline Station average & -1.3 & -0.8 & -0.3 & +1.2 & +1.3 \\
\hline
\end{tabular}

Although, in most cases, the summed traces do not greatly improve the overall $\mathrm{s} / \mathrm{n}$ ratio compared to the best station trace, the confidence of reading the normally small signal onset is significantly improved by the visual and statistical correlation afforded by the array. As a measure of how much this type of analysis can improve readings of $S$-wave onsets, it is useful to compare readings here with available seismological bulletins. $S$-wave arrival times have previously been read and reported in station bulletins for stations UPP and UME in Cases 1, 5 , and 6 . Table 6 indicates corrections of the bulletin readings as follows: Case $1, \operatorname{UPP}(e S)-0.1, \mathrm{UME}(i S)+8.6$; Case 6 , $\mathrm{UPP}(i S)+1.4, \mathrm{UME}(i S)+2.8$. The onset of $S$ in Case 5 is not good enough to apply corrections with confidence. The remaining cases have $S$ waves that were not normally read for bulletins because of low amplitude (see Figure 6) or lack of a distinct onset.

Geological variations along the different paths to the stations in the array can change the velocities of $S V$ and $S H$. In general the change will not be the same for both $S V$ and $S H$. For example, in Case 1, the $S H$ at KON arrives about 1-2 seconds later than at the other stations when $S V$ is used for alignment as can be seen in Figures 3 (b) and 4 (b). The most likely place for path differences to exist is near the stations in the crust and/or upper mantle. Inspection of the map in Figure 1 shows that the main difference in the Case 1 path to KON is that it lies to the edge of the Fennoscandian shield, whereas the other paths are almost entirely in the shield area as they emerge from depth. This would imply a higher $S H / S V$ velocity ratio under the shield area than under the adjacent area to the northwest which has a history of more recent tectonic activity. However, further studies of this type need to be made to support this result. 
Crust and upper mantle variations over the array can cause a systematic station residual with respect to the other stations. Although the number of cases here is insufficient to do a statistically meaningful analysis of systematic residuals, some trends can be seen. To get a relative set of residuals, the average residual for each case is subtracted from the $S$ residuals of Table 6 . For Case 1, $S H$ is used and for Case 2, since $S V$ is probably $S p$, the six-second $S H-S p$ difference of Case 1 is subtracted from Case 2 residuals. The relative residuals are shown in Table 7 along with their averages. UPP shows the smallest variation and an average residual of -1.3 . The remaining station residuals, although showing larger variations, mirror the general crustal structure of the Fennoscandian region. UPP, UME, and NUR show negative average residuals. These stations are on the granitic Fennoscandian shield with NUR in the eastern portion of the shield. COP overlies thick sections of lower-velocity chalk and limestone beds, and KON overlies a thick sequence of lower-velocity metamorphic rocks, which explains the positive average residual at both of these stations.

\section{ACKNOWLEDGMENTS}

This work was done while the author was at the Seismological Institute, Uppsala, Sweden, with the support of Sweden-America Foundation and Fulbright-Hays grants. The research was partially sponsored by the Cambridge Research Laboratories of the Office of Aerospace Research, United States Air Force, through its European Office, as part of the Advanced Research Projects Agency's project VELA UNIFORM, under contract AF 61(052)-702. Professor Markus Båth suggested this project, and his support and advice throughout the work is greatly appreciated. Dr. Bo Jansson of the Swedish Defense Research Institute supplied helpful advice and some computer programs. The author wishes to thank the directors of the seismological institutes at Copenhagen, Denmark; Bergen, Norway; and Helsinki, Finland, for the use of seismic recordings and the Swedish Defense Research Institute in Stockholm for the use of their facilities. Records from UPP were made with instruments on loan from Lamont-Doherty Geological Observatory, Columbia University, as part of the IGY program. The author is currently receiving support from NASA Research Grant NGR 05-002-069 at the California Institute of Technology.

\section{REFERENCES}

Baker, G. T., J. A. Bonner and R. B. Roden (1966). Initial analysis of long-period large-aperture data recorded at the Tonto Forest Seismological Observatory in 1965, Array Research Special Report 16, Texas Inst. Inc., $76 \mathrm{pp}$.

Băth, M. (1949). An investigation of the Uppsala microseisms, $P h . D$. Thesis, The University, Uppsala, Sweden, 168 pp.

Båth, M. (1961). Polarization of transverse seismic waves, Geophys. J of the Royal Astron. Soc, 4, 106-123.

Băth, M. and A. L. Arroyo (1963). Pa and $S a$ waves and the upper mantle, Geofisica Pura e Applicata $\mathbf{5 6} 6,67-92$.

Băth, M. and R. Stefánsson (1966). S-P conversion at the base of the crust, Ann. Geofis. (Rome) $19,119-130$.

Blackman, R. B. and J. W. Tukey (1959). The measurement of power spectra, Dover, London, $180 \mathrm{pp}$.

Capon, J., R. J. Greenfield and R. T. Lacoss (1966). Off-line processing results for the large aperture seismic array, Technical Note 1966-37, Lincoln Lab., Mass. Inst. of Tech., Lexington, Mass.

Capon, J., R. J. Greenfield and R. T. Lacoss (1967). Long-period results in seismic discrimination, Semiannual Tech. Summary Rept. to the ARPA for $1 \mathrm{July}-31$ Dec 1966.

Christoffersson, A. and B. Jansson (1967). Maximum-likelihood estimation of an unknown signal in multiple Gaussian noise with known covariance matrix, Unpubl. manuscript, $12 \mathrm{pp}$.

Denham, D. (1963). The use of geophone groups to improve the signal-to-noise ratio of the first arrival in refraction shooting, Geophys. Prosp. 11, 389-408.

Husebye, E. S. (1965). Correction analysis of Jeffreys-Bullen travel-time tables, Bull. Seism. Soc. Am. 55, 1023-1038. 
Husebye, E. S. and B. Jansson (1966). Application of array data processing techniques to the Swedish seismograph stations, Pure and Applied Geophys. 63, 82-104.

Jeffreys, H. and K. E. Bullen (1940). Seismological tables, British Assoc. for the Advanc. of Sci., Gray-Milne Trust, London, $48 \mathrm{pp}$.

Kelly, E. J. and M. J. Levin (1964). Signal parameter estimation for seismometer arrays, Technical Rept. 339, Lincoln Lab., DDC 435489, Mass. Inst. of Tech., Lexington, Mass.

Korkman, K. (1968). Aftershock $P$-wave spectra and dynamic features of the Aleutian Islands earthquake sequence of February 4, 1965, Tectonophysics. 5, 245-266.

Ritsema, A. R. (1958). (i-delta)-curves for bodily seismic waves of any focal depth, Lembaga Meteorologi dan Geofisik, Djakarta Republik Indonesia, Verhandelingen No. 54.

Santô, T. A. (1962). Energy sources of microseisms in Sweden, Ann. Geofis. (Rome) 15, 335-377.

VESIAC (1962). Problems in seismic background noise, VESIAC Advisory Rept. 4410-32-X, Univ. of Mich., Ann Arbor, Mich.

Califormia Institute of Technologx

Seismological Laboratory

Pasadena, California

Manuscript received May 22, 1968.

\section{Appendix \\ Definition of Statistical Terms}

The following material defines the common statistics that are used above to analyze the digitized time series. For a more complete discussion of the statistics used in this paper, see Husebye and Jansson (1966) or Blackman and Tukey (1959).

Estimated quantities used in the statistical calculations are defined as follows:

$x(t), y(t), \cdots \quad$ Discrete (digitized) readings of the records of a signal at different stations

$\langle x\rangle,\langle y\rangle, \cdots \quad$ Mean values of discrete time series functions

$\sigma_{x}^{2}, \sigma_{y}^{2}, \ldots \quad$ Variance of discrete time series functions

$c_{x}(l) \quad$ Lagged covariance of the $x(t)$ series relative to itself

$c_{x y}(l) \quad$ Lagged covariance of the $x(t)$ series relative to the $y(t)$ series

$\Delta t \quad$ Digitizing interval

$l=0,1, \cdots, m$ Time lags used, corresponding to $t, t+\Delta t, t+2 \Delta t, \cdots, t+m \Delta t$

$c_{x}(l) / \sigma_{x}^{2} \quad$ Normalized auto-correlation function of $x(t)$

$c_{x y}(l) / \sigma_{x} \sigma_{y} \quad$ Normalized cross-correlation function between $x(t)$ and $y(t)$

$X(k) \quad$ Power spectrum of $x(t)$

$C_{x y}(k), Q_{x y}(k) \quad$ Real part (co-spectrum) and imaginary part (quadrature spectrum), respectively, of the cross-spectrum of the series $x(t)$ and $y(t)$

$k=0,1, \cdots, m$ Indices of the frequency bands

$R_{x y}(k) \quad$ Coherency between $x(t)$ and $y(t)$

$\theta_{x y}(k) \quad$ Phase lag of $y(t)$ relative to $x(t)$

From the means $\langle x\rangle,\langle y\rangle, \cdots$ and the variances $\sigma_{x}{ }^{2}, \sigma_{y}{ }^{2}, \cdots$ of the time series $x(t)$, $y(t), \cdots$, the lagged covariances are calculated by the formulas

$$
\begin{gathered}
c_{x}(l)=n^{-1} \sum_{x=1}^{n}\left(x_{s}-\langle x\rangle\right)\left(x_{s+l}-\langle x\rangle\right) \\
c_{x y}(l)=n^{-1} \sum_{s=1}^{n}\left(x_{s}-\langle x\rangle\right)\left(y_{s+l}-\langle y\rangle\right)
\end{gathered}
$$

for $l=0,1,2, \cdots, m$. 
The power spectrum and cross-spectrum are calculated by the following:

$$
\begin{aligned}
X(k) & =\frac{\delta(k)}{m}\left[c_{x}(0)+\sum_{l=1}^{m}\left(c_{x}(l) \frac{m-l+1}{m+1} \cos \frac{\pi k l}{m}\right)\right] \\
C_{x y}(k) & =\frac{\delta(k)}{m}\left[c_{x y}(0)+\sum_{l=1}^{m}\left(\frac{1}{2} \frac{m-l+1}{m+1} \cos \frac{\pi k l}{m}\right)\left[c_{x y}(l)+c_{y x}(l)\right]\right] \\
Q_{x y}(k) & =\frac{1}{m}\left[\sum_{l=1}^{m}\left(\frac{1}{2} \frac{m-l+1}{m+1} \sin \frac{\pi k l}{m}\right)\left[c_{x y}(l)-c_{y x}(l)\right]\right]
\end{aligned}
$$

for $k=0,1, \cdots, m$. In these relations $\delta(k)=\frac{1}{2}$ when $k=0$ and is unity otherwise. $X(k)$ measures the proportion of the total power of $x(t)$ in a frequency band of roughly $1.3 /(m \Delta t)$ cps in width, centered around $k /(2 m \Delta t)$ oscillations per time interval. $Y(k)$ is the same parameter corresponding to the $y(t)$ series.

The coherency $R_{x y}(k)$ and phase $\operatorname{lag} \theta_{x y}(k)$ for the time series $x(t)$ and $y(t)$ are formed by the relations

$$
\begin{aligned}
& R_{x y}(k)=\frac{\left[C_{x y}(k)^{2}+Q_{x y}(k)^{2}\right]^{1 / 2}}{X(k) Y(k)} \\
& \theta_{x y}(k)=\arctan \frac{Q_{x y}(k)}{C_{x y}(k)}
\end{aligned}
$$

$R_{x y}(k)$ measures the strength of association between the two series in the $k^{\text {th }}$ band, and $\theta_{x y}(k)$ is the phase lag in the $y(t)$ series relative to the $x(t)$ series at the frequency $k /(2 m \Delta t)$.

Signal length is usually set at 40 seconds, which gives $n \simeq 80 . m$ is chosen to be 20 , and for these values Blackman and Tukey's (1959) test of the reliability of spectra shows that fractional errors of about 30 per cent either way can be expected in estimated spectra. 